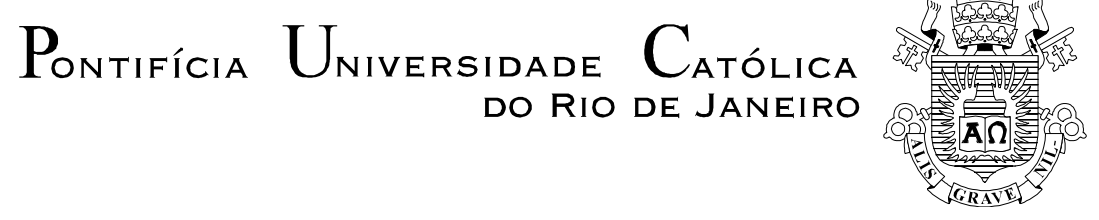

Caio Dalbert Cunha de Avellar

\title{
O Tribunal Penal Internacional e a Constituição Federal de 88
}

\section{Dissertação de Mestrado}

Dissertação apresentada ao Programa de Pósgraduação em Direito da PUC-Rio como requisito parcial para obtenção do título de Mestre em Direito.

Orientador: Prof. José María Gómez 


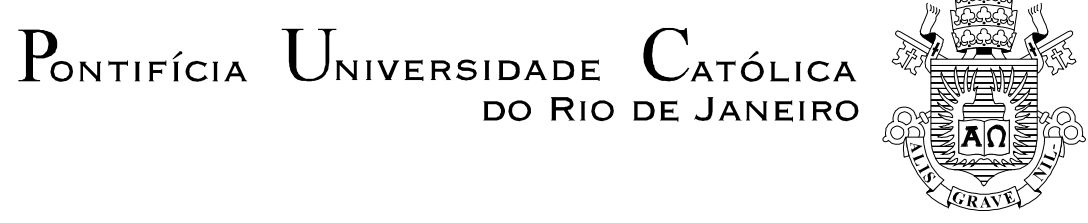

Caio Dalbert Cunha de Avellar

\title{
O Tribunal Penal Internacional e Constituição Federal de 88
}

Dissertação apresentada como requisito parcial para obtenção do grau de Mestre pelo Programa de Pós-graduação em Direito da PUC-Rio. Aprovada pela Comissão Examinadora abaixo assinada.

\author{
Prof. José María Gómez \\ Orientador \\ Departamento de Direito - PUC-Rio
}

Prof. João Ricardo W. Dornelles Departamento de Direito - PUC-Rio

Profa. Márcia Nina Bernardes

Departamento de Direito - PUC-Rio

Profa. Mônica Herz

Vice-Decana de Pós-Graduação do Centro de

Ciências Sociais - PUC-Rio

Rio de Janeiro, 04 de julho de 2012 
Todos os direitos reservados. É proibida a reprodução total ou parcial do trabalho sem autorização da universidade, do autor e do orientador.

\section{Caio Dalbert Cunha de Avellar}

Graduou-se em Direito em julho de 2006 pela Universidade Federal de Mato Grosso do Sul - Campus do Pantanal. Exerce o cargo de Professor na mesma instituição e unidade, em regime de dedicação exclusiva, lotado na Coordenação do Curso de Direito, na área de Direito Público.

Ficha catalográfica

Avellar, Caio Dalbert Cunha de Avellar.
O Tribunal Penal Internacional e Constituição Federal
de 88/ Caio Dalbert Cunha de Avellar; Orientador:
José Maria Gómez - Rio de Janeiro: PUC,
Departamento de Direito, 2012.

98 f. ; $30 \mathrm{~cm}$

Dissertação (mestrado) - Pontifícia Universidade Católica do Rio de Janeiro, Departamento de Direito.

Inclui referências bibliográficas.

1. Direito - teses. 2. TPI. 3. constituição. 4. compatibilidade 5. crimes internacionais. 6. direitos humanos. I. Gómez, José Maria. II. Pontifícia Universidade Católica do Rio de Janeiro. Departamento de Direito. III. Título. 
À Priscilla, minha amada esposa, por tudo o que representa em minha vida. Aos meus pais, Wibert e Dalva, pelo carinho, dedicação e exemplo demonstrados ao longo da vida. À Lilian, minha querida irmã, por sempre fazer parte da minha existência. 


\section{Agradecimentos}

De início, agradeço a Deus, por todo o plano que Ele fez e continua a fazer em minha vida, plano esse que nunca falha ou dá errado.

Meu orientador, Prof. Gómez, pelo apoio incondicional dado neste momento, por vezes um pouco tenso, de escrita da dissertação. Ratifico aqui o que certa feita lhe disse: "Quem dera eu, com professor que sou, ter apenas uma parcela de sua cultura e carisma!" Meu muito obrigado!

Novamente digna de nota a menção às pessoas que estão na dedicatória, pela importância sem igual que possuem pra mim.

Priscilla, que tanto amo, agradeço-lhe por todos os momentos que passamos e por todos aquele que vamos continuar passando juntos. Obrigado pelos conselhos e palavras de afeto sempre que precisei, pelo seu amor, por tudo mesmo.

Meus pais, Wibert e Dalva, eterna fonte de amor e carinho, que mesmo nos momentos mais difíceis não esmoreceram e lutaram para dar um ensino de qualidade para mim e para minha irmã, o que contribuiu para nossa evolução pessoal e profissional.

Lilian, minha maninha, que mesmo sem saber, algumas vezes me faz exercitar o dom da paciência! Obrigado pela grande companheira que você é, sendo muito mais do que essencial e especial pra mim.

Aos amigos que possuo em Corumbá, cidade que tanto amo.

Aos colegas e amigos que fiz no curso, foi muito bom estar com vocês nesse tempo. Espero que possamos continuar mantendo contato.

Caros Carmem e Anderson, colaboradores da PUC-Rio, vocês nem imaginam o quanto nos ajudaram, obrigado por tudo.

Aos professores, que compartilharam conosco seus conhecimentos e experiências de vida. Aprendemos muito, graças à dedicação de todo o corpo docente, com um carinho especial aos professores João Ricardo e Márcia, que aceitaram o convite para participarem da minha banca e, com seus sábios ensinamentos, contribuíram para o deslinde desse trabalho.

Aos meus alunos do curso de Direito da UFMS/CPAN, pelo convívio e pela oportunidade que eu tenho de aprender com vocês a cada dia que passa. Obrigado por todo o carinho e compreensão.

Ao grande amigo Celso Philbois, o qual me deu a oportunidade de realizar o curso, fazendo assim com que um sonho se tornasse realidade. Curso esse em uma das instituições mais respeitadas do país e em uma das cidades mais belas que existe. Não tenho palavras para expressar minha gratidão. Sem sua ajuda, nada disso seria possível. Obrigado mesmo! 


\section{Resumo}

Avellar, Caio Dalbert Cunha de; Gómez, José Maria. O Tribunal Penal Internacional e a Constituição de 1988. Rio de Janeiro 2012. 98p. Dissertação de Mestrado. Departamento de Direito, Pontifícia Universidade Católica do Rio de Janeiro.

O objeto da presente dissertação é o estudo do Tribunal Penal Internacional, optando-se por delimitar seu campo para a análise e compatibilidade deste com o ordenamento constitucional pátrio. Feito esse recorte, não será o diploma que o instituiu, qual seja, o Estatuto de Roma, analisado à exaustão, sendo certo que dispositivos referentes, por exemplo, ao financiamento do Tribunal, modo de designação dos juízes, órgãos que o compõem, processo e julgamento dos responsáveis etc., não serão verificados, ou apenas se fará uma breve menção, quando houver necessidade. Os crimes serão vistos e a evolução até o TPI chegar nos moldes atuais, bem como seus fundamentos norteadores, objetivando contextualizar o leitor de sua principais características e o que o mundo como um todo teve que passar para que houvesse a instituição de um organismo jurisdicional de caráter permanente apto a julgar aqueles que praticam os mais repulsivos delitos contra os direitos humanos.

\section{Palavras-chave}

TPI; constituição; compatibilidade; crimes internacionais; direitos humanos. 


\section{Resumen}

Avellar, Caio Dalbert Cunha de. El Tribunal Penal Internacional y la Constitución de 1988. Rio de Janeiro 2012. 98p. Tesina de Maestría. Departamento de Derecho, Pontificia Universidade Católica do Rio de Janeiro.

El objeto de la presente tesina es el estudio del Tribunal Penal Internacional, para el cual se ha optado por delimitar su campo para el análisis y compatibilidad de éste con el ordenamiento constitucional patrio. Hecho tal recorte, no será el diploma que lo ha instituido, es decir, el Estatuto de Roma, analizado exhaustivamente, siendo cierto que determinados dispositivos, por ejemplo, al financiamiento del Tribunal, modo de designación de los jueces, órganos que lo componen, proceso y juzgamiento de los responsables etc, no serán verificados, o apenas se hará una breve mención, cuando haya necesidad. Los crímenes serán vistos y la evolución hasta que el TPI logre los moldes actuales, bien como sus fundamentos orientadores, objetivando contextualizar al lector de sus principales características y lo que el mundo, como un todo, tuvo que pasar para que hubiera la institución de un organismo jurisdiccional de carácter permanente apto a juzgar aquellos que practican los más repulsivos delitos contra los derechos humanos.

\section{Palabras claves}

CPI; constitución; compatibilidad; crímenes internacionales; derechos humanos. 


\section{Sumário}

1. Introdução

11

2. Globalização e os Direitos Humanos 18

2.1 Comissão e Corte Interamericana de Direitos Humanos 18

2.2 Direito Internacional dos Direitos Humanos 19

2.3 Os Direitos Humanos, a América Latina e o Brasil 22

2.4 Os efeitos da ausência de normativa internacional 24

2.5 TPI é mecanismo de defesa dos Direitos Humanos? 28

$\begin{array}{ll}2.6 \text { Evolução até o TPI } & 30\end{array}$

2.6.1 Tribunais de Nuremberg e Tóquio 30

2.6.2 Tribunais para a antiga lugoslávia e de Ruanda 33

2.7 Princípios e fundamentos do TPI 36

3. Direito Penal Internacional 39

3.1 Considerações gerais $\quad 44$

3.2 Processo de incorporação 58

4. Crimes de competência do TPI 61

4.1 Crimes em espécie 62

4.1.1 Crime de genocídio 63

$\begin{array}{ll}\text { 4.1.2 Crimes contra a humanidade } & 65\end{array}$

$\begin{array}{ll}4.1 .3 \text { crimes de guerra } & 71\end{array}$

$\begin{array}{ll}\text { 4.1.4 Crime de agressão } & 74\end{array}$

5. Conflitos aparentes entre o TPI e ordenamento brasileiro 76

5.1. Extradição e entrega 76 
5.2. Imunidades e foro por prerrogativa de função

5.3. Coisa julgada $\quad 80$

5.4. Possibilidade de aplicação da pena de prisão perpétua 81

5.5 O STJ no processo de homologação de sentenças estrangeiras

5.6 Necessidade de regulamentação 85

6. Conclusão 87

7. Referência Bibliográficas 


\section{SIGLAS}

ADPF - Arguição de Descumprimento de Preceito Fundamental

CF - Constituição Federal

CIDH - Comissão Interamericana de Direitos Humanos

CPP - Código de Processo Penal

DJ - Diário da Justiça

ONG - Organização Não Governamental

ONU - Organização das Nações Unidas

RE - Recurso Extraordinário

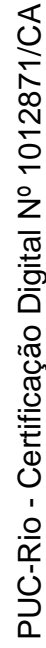

RESP - Recurso Especial

STF - Supremo Tribunal Federal

STJ - Superior Tribunal de Justiça

TPI - Tribunal Penal Internacional 